\title{
Design of Ignition Targets for the National Ignition Facility
}

S.W. Haan, T.R. Dittrich, M.M. Marinak and D.E. Hinkel

This article was submitted to

First International Conference on Inertial Fusion Sciences and Applications

Bordeaux, France

September 12-17, 1999

U.S. Department of Energy

\section{November 1, 1999}

Lawrence

Livermore

National

Laboratory 


\section{DISCLAIMER}

This document was prepared as an account of work sponsored by an agency of the United States Government. Neither the United States Government nor the University of California nor any of their employees, makes any warranty, express or implied, or assumes any legal liability or responsibility for the accuracy, completeness, or usefulness of any information, apparatus, product, or process disclosed, or represents that its use would not infringe privately owned rights. Reference herein to any specific commercial product, process, or service by trade name, trademark, manufacturer, or otherwise, does not necessarily constitute or imply its endorsement, recommendation, or favoring by the United States Government or the University of California. The views and opinions of authors expressed herein do not necessarily state or reflect those of the United States Government or the University of California, and shall not be used for advertising or product endorsement purposes.

This is a preprint of a paper intended for publication in a journal or proceedings. Since changes may be made before publication, this preprint is made available with the understanding that it will not be cited or reproduced without the permission of the author.

This work was performed under the auspices of the U.S. Dept. of Energy at LLNL under contract no. W7405-Eng-48.

This report has been reproduced directly from the best available copy.

Available to DOE and DOE contractors from the

Office of Scientific and Technical Information

P.O. Box 62, Oak Ridge, TN 37831

Prices available from (423) 576-8401

http://apollo.osti.gov/bridge/

Available to the public from the National Technical Information Service

U.S. Department of Commerce 5285 Port Royal Rd., Springfield, VA 22161 http://www.ntis.gov/

OR

Lawrence Livermore National Laboratory Technical Information Department's Digital Library http://www.llnl.gov/tid/Library.html 


\title{
Design of ignition targets for the National Ignition Facility
}

\author{
Steven W. Haan, T. R. Dittrich, M. M. Marinak, and D. E. Hinkel \\ Lawrence Livermore National Laboratory \\ Livermore CA 94550
}

\begin{abstract}
This is a brief update on the work being done to design ignition targets for the National Ignition Facility. Updates are presented on three areas of current activity : improvements in modeling, work on a variety of targets spanning the parameter space of possible ignition targets ; and the setting of specifications for target fabrication and diagnostics. Highlights of recent activity include : a simulation of the Rayleigh-Taylor instability growth on in imploding capsule, done in $3 \mathrm{D}$ on a $72^{\circ}$ by $72^{\circ}$ wedge, with enough zones to resolve modes out to 100 ; and designs of targets at $250 \mathrm{eV}$ and $350 \mathrm{eV}$, as well as the baseline $300 \mathrm{eV}$; and variation of the central DT gas density, which influences both the Rayleigh-Taylor growth and the smoothness of the DT ice layer.
\end{abstract}

\section{Introduction}

The National Ignition Facility is a large laser being built at Lawrence Livermore National Laboratory. One of its principal goals is to demonstrate the ignition and burn of targets containing deuterium-tritium fuel. Work has been going on for about 10 years on the design of these targets ; this article is an update on the status of that work. Results are presented in four areas : improvements in the modeling of the baseline targets ; design work at different drive temperatures ; setting of target fabrication specifications ; and simulations being used to define the diagnostic instruments needed for ignition implosions.

The basic ideas behind the ignition targets are described in refs. [1-4]. The laser is described in other articles in this proceedings. The baseline ignition target is shown in figure 1 , with radiation drive and laser power shown in figure 2.
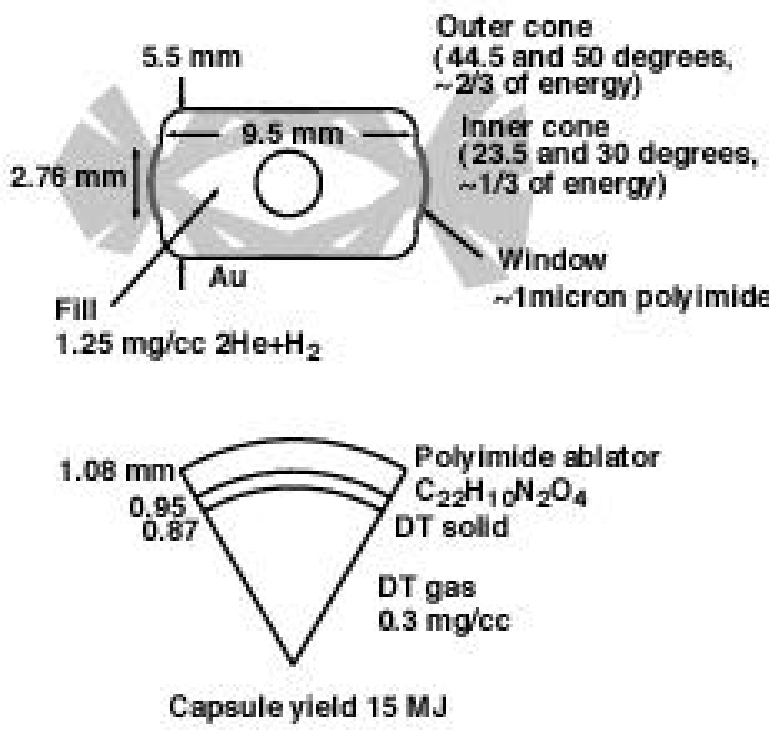

Figure 1. Baseline indirect drive ignition target. This target uses 1.3 MJ of absorbed laser light.

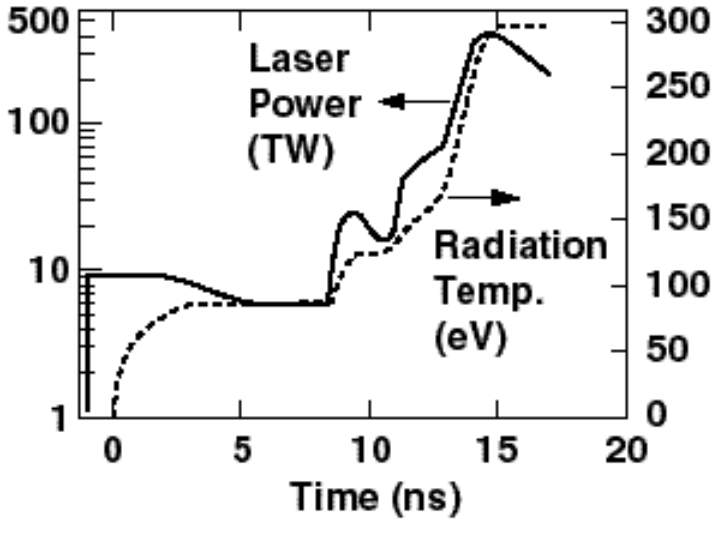

Figure 2. Laser power and radiation temperature driving the target shown in figure 1. 


\section{Improvements in modeling}

The design simulations for the NIF targets have mostly been done with two codes, HYDRA [5] and LASNEX [6]. LASNEX is a 2-dimensional radiation hydrodynamics code with very complete modeling of most relevant physical processes. HYDRA is a relatively new 3D radiation hydrodynamics code with modern hydrodynamics algorithms and Arbitrary Lagrange Eulerian capability. It has all of the physics necessary for NIF ignition capsule implosions, including multi-group radiation diffusion, electron conduction, alpha particle transport, and neutron energy deposition. HYDRA has been used quite extensively in analysis of Nova experiments and has been well verified. [5,7]

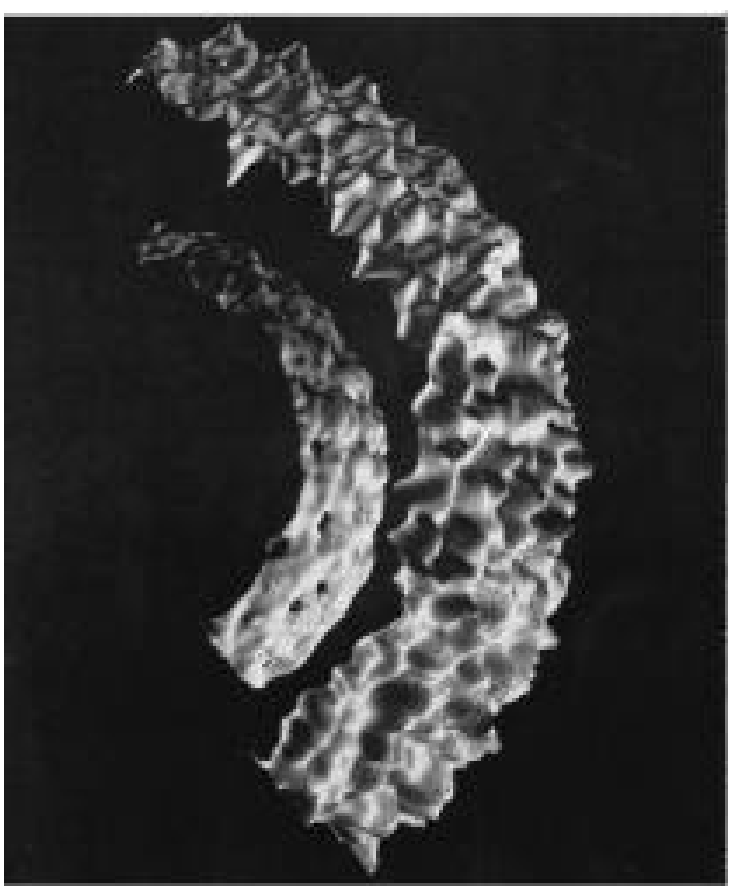

Figure 3. Density isocontour at $13.6 \mathrm{~g} / \mathrm{cc}$ of imploding NIF shell prior to ignition, in HYDRA simulation by M. Marinak. The ice and ablator surface were roughened with 1 $\mu \mathrm{m}$ and $20 \mathrm{~nm}$ perturbations respectively, with spectra based on characterization of real surfaces.

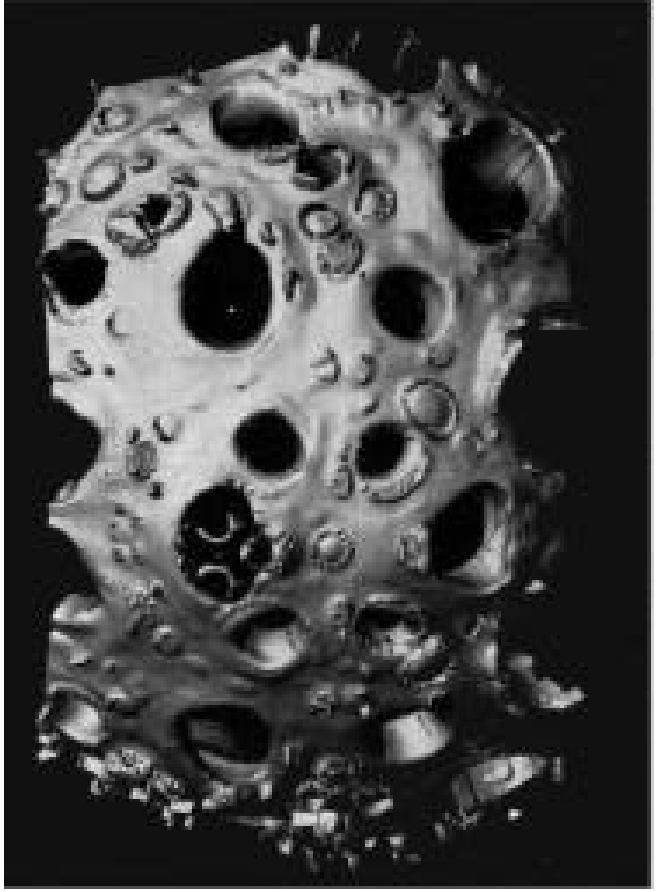

Figure 4. Same simulation during burn (1MJ cumulative yield at this time). The total yield for this simulation is $15.4 \mathrm{MJ}$

The recent simulations have been done on a $72^{\circ}$ by $72^{\circ}$ wedge, with enough zones to resolve modes up to 100. Simulations were done on a beryllium-ablator target, the same target used in simulations reported previously.[8] Initial perturbations were similar to those used in other work. As described in ref. 6, they are based on characterization of Nova capsule surfaces, and of DT ice layers in _beta-layering experiments. Initial roughnesses were $1 \mu \mathrm{m}$ rms for the ice, and $20 \mathrm{~nm}$ rms for the beryllium, with a multi-mode spectrum initializing modes from around $2\left(1 / 2\right.$ wave in $\left.72^{\circ}\right)$ to 100 . The capsule performs well in the simulation, producing $15.4 \mathrm{MJ}$ of fusion yield. Figures 3 and 4 show density isocontours at a time prior to ignition and after burn is under way, respectively. Figure 3 shows the growth of short wavelength perturbations to amplitudes somewhat less than the shell thickness. Figure 4 shows two interesting features. There are low density regions where bubbles of hot fuel have risen through the decelerating shell. There are also crater-like features on the outer surface. At these points, fingers of beryllium have reached down to the stagnation shock, which 
defines the outer isocontour. Outside of the craters the density isocontour is in DT ; inside the craters, it is in beryllium, with the material interface forming the crater. Both of these features are also seen in 2D multimode simulations, although the nonlinear perturbation growth is quantitatively larger in three dimensions. Also, of course, the features are 2D rings in the 2D simulations, rather than being round spots as in 3D. This work will be described in more detail in a future publication by M. Marinak, who both wrote the code and did the simulations.

\section{Design work at the edges of parameter space : $250 \mathrm{eV}$ and $350 \mathrm{eV}$}

Most NIF target design work has been at $300 \mathrm{eV}$, which is the temperature currently considered most likely to produce ignition. However, the optimum tradeoff of the various physics issues may result in our operating at some other temperature, and it is important for us to understand the issues and requirements at the different temperatures. By intent these designs stress some physics issues and will not look robust in all regards.

A design at $350 \mathrm{eV}$, by $\mathrm{D}$. Hinkel, is close to being a 0.65 scale of the baseline. The hohlraum is $6.6 \mathrm{~mm}$ long by $3.56 \mathrm{~mm}$ diameter. The capsule is beryllium, outer radius 710 $\mu \mathrm{m}$, with a layer of clean Be and a layer of $1 \% \mathrm{Cu}$-doped $\mathrm{Be}$ This target performs well in integrated simulations, giving $70 \%$ of clean 1D yield. The integrated simulations required increasing case-to-capsule ratio from 2.5 to 3 (at waist) in order to avoid both hohlraum filling and asymmetric pressure on capsule from the hohlraum fill gas. At case-to-capsule ratio 2.5, various gas fills were considered; at low gas fills, the hohlraum filled unacceptably, while at higher gas fills a pressure spike on axis perturbed the capsule causing an asymmetric implosion even with the radiation on the capsule artificially symmetrized. designs operating at $300 \mathrm{eV}$ or lower there is an operating regime between these two failure modes, but at $350 \mathrm{eV}$ the case-to-capsule ratio has to be increased before a satisfactory gas-fill can be found. Estimates of filamentation in the plasma typical of this hohlraum, done with the code $\mathrm{pF} 3 \mathrm{D}$, suggest we may need SSD with as much as $6 \AA$ of bandwidth (at $1 \mu \mathrm{m}$ ) to control the filamentation. Polarization smoothing is also being considered, and may reduce the bandwidth requirement. Rayleigh-Taylor analysis of this target shows very low growth. It can tolerate 5 micron DT rms and >50 nm ablator rms.

A very small design at $250 \mathrm{eV}$ has been described previously [9] ; somewhat bigger designs, corresponding to $1.3 \mathrm{MJ}$ of laser light, have now been considered in more detail. As was the case for the design described in ref. 7, the Rayleigh-Taylor growth is quite severe. An important option at $250 \mathrm{eV}$ may be to increase the capsule coupling efficiency, as described by Suter elsewhere in this proceedings. It may be possible to increase the energy absorbed by the capsule to as much as four times what was assumed in the $250 \mathrm{eV}$ work to date. This will make the Rayleigh-Taylor growth acceptably small, although detailed design work on this remains to be done. Suter's proposed reoptimization of the hohlraum may also allow for quite high gains, close to $100 \mathrm{MJ}$, from $250 \mathrm{eV}$ targets.

\section{Target Fabrication Specifications}

In addition to Rayleigh-Taylor analysis for each target we are considering, some work has been done dedicated to determining target fabrication specifications in two areas : low mode deviations from sphericity, and the performance vs. central gas density.

The low-mode specification is based on linear analysis. We did a set of linear-regime single mode simulations with various modes in order to determine a growth factor for each mode number. We also did large-amplitude simulations with the various modes to determine how large a final amplitude could be tolerated for each mode. These results can be combined, with a safety factor, to determine a table of effective maximum amplitudes for each mode. There remain details to work out before it would be appropriate to publish the table, so it will not be presented here.

The other area of work to describe here is considerations of the central gas density. It appears likely, from work on characterization of the DT ice layer, that the quality of the 
surface is a strong function of the operating temperature. The surface is likely to be smoother at temperatures close to the triple point, at $19.8 \mathrm{~K}$ at $0.62 \mathrm{mg} / \mathrm{cc}$, while the target performance has a somewhat weaker contrary dependence. Previously the designs have usually stipulated a

central density of $0.3 \mathrm{mg} / \mathrm{cc}$, corresponding to an operating temperature of $18.3 \mathrm{~K}$. The Rayleigh-Taylor sensitivity of the baseline $300 \mathrm{eV}$ polyimide design is shown in figure 5, contrasting the growth for the two different gas densities. While the performance suffers somewhat at higher gas fill, and the ablator surface specification is somewhat tighter, it appears that there is an option of operating at the triple-point density of $0.6 \mathrm{mg} / \mathrm{cc}$. This may be necessary if the surface roughness is more than $3 \mu \mathrm{m}$ at $18.7 \mathrm{~K}$, it having been characterized at about $1 \mu \mathrm{m}$ rms at $19.8 \mathrm{~K}$.
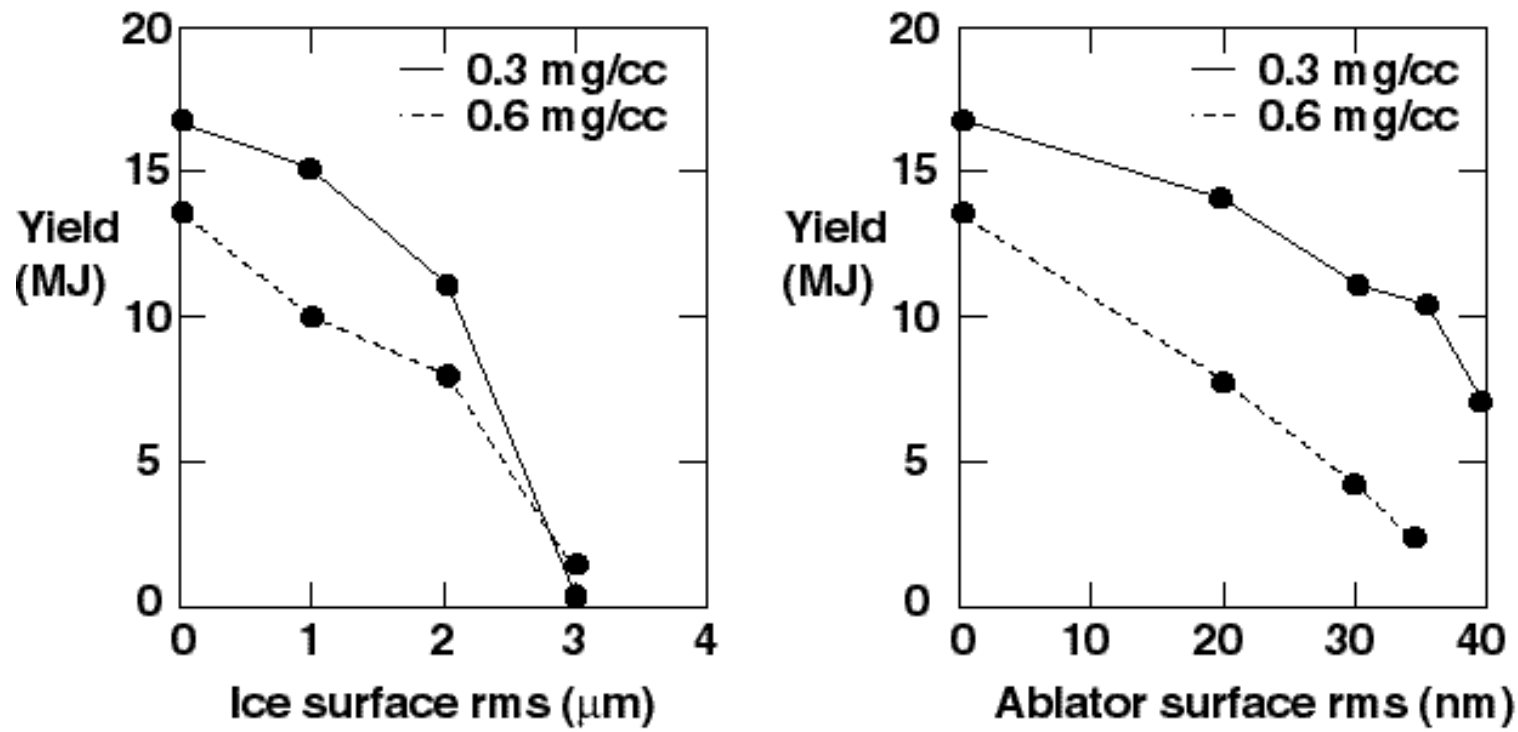

Figure 5. Yield vs. initial amplitude showing the Rayleigh-Taylor instability sensitivity for the $300 \mathrm{eV}$ polyimide capsule, at two different operating temperatures (equivalent to two different central gas densities, as indicated). The higher density of $0.6 \mathrm{mg} / \mathrm{cc}$ is close to the triple-point gas density, while most design work has been done at $0.3 \mathrm{mg} / \mathrm{cc}$, corresponding to a temperature 1.3 $\mathrm{K}$ lower. Although performance is worse, and specification tighter, at the higher gas density, the ice surface may be significantly smoother at this temperature and the optimum operating point may be the higher temperature and density.

\section{Diagnostic specifications}

A final area of active work is the simulation of target output as needed to optimize the diagnostic instruments being planned for the ignition implosions. Proposed diagnostics include :

$>$ the usual neutron yield, with time-of-flight broadening to give ion temperature ;

$>$ secondary and tertiary neutrons to get pr measurements (the details of this are an important topic for near-term future work) ;

$>$ the charged particle output (results from Petrasso et al. on Omega suggest that this will be very interesting, and they have proposed high energy protons as a shell pr measurement [10] ;

$>$ a reaction history measurement, possibly based on the direct $\gamma$-rays produced at a small rate in $\mathrm{D}-\mathrm{T}$ reactions ;

$>$ imaging in neutrons and high energy x-rays, as discussed below.

We would like to put together a detailed description of how each of these would manifest various possible failure modes, so that we can say ahead of time how any likely failure 
mechanism will be diagnosed. That will help us to set specifications for the instruments

High resolution images would be very valuable, both in neutrons and x-rays. It is likely that the size of the images will be valuable ; for example, shock timing problems will probably result in images that are bigger than expected, while mix will probably reduce the size of the images. If they are nonreproducibly out of round, that will suggest problems with power balance, low mode target fabrication problems, or too-large laser-plasma instabilities, which would have exactly the same effect on the implosion. If the images are reproducibly out-of-round, it will suggest problems with intrinsic hohlraum asymmetry or « aligned » target fabrication issues such as the cryo layer roundness or the tent supporting the capsule.

Besides this rather large list of possible inferences from each case, work on images has also suggested that the inference to be made is not necessarily simple. For example, an implosion with a P2 asymmetry in target fabrication (the shell too thin at the poles) comes in, bounces on the poles, and produces an image that is somewhat elongated along the poles (« sausaged ») and pinched in around the waist. So images will have to be interpreted carefully, probably with code simulations as guides.

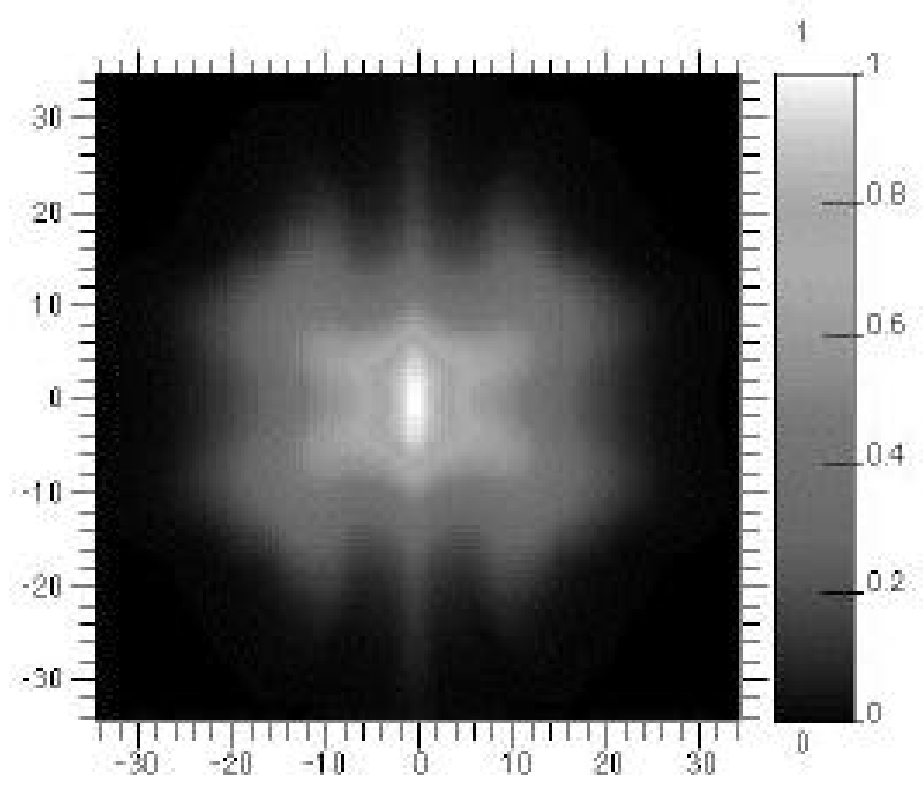

Figure 6. Simulated neutron image, brightness vs. position in microns.

One possible image, typical of what we might want to see, is in figure.6. This is a simulation that was made to «fizzle » by running without alpha particle deposition. Similar images have been made in simulations with too-large $\mathrm{P}_{6}$ and $\mathrm{P}_{8}$ asymmetries. The simulation shown also includes short-wavelength surface perturbations in even modes 2 through 40 . It produced $27 \mathrm{~kJ}$ of yield $\left(9.7 \times 10^{15}\right.$ neutrons), with peak ion temperature $9.4 \mathrm{keV}$ and burnweighted ion temperature (such as would be seen from neutron time-of-flight broadening) 4.8 $\mathrm{keV}$. The structure, which is caused primarily by the $\mathrm{P}_{6}$ and $\mathrm{P}_{8}$ hohlraum asymmetry, is small enough that imaging with resolution of $5 \mu \mathrm{m}$ or better would be valuable.

High energy $\mathrm{x}$-ray images are quite similar to the neutron image shown. X-rays are produced by bremsstrahlung emission from the very hot fuel, and at energies above about 10 $\mathrm{keV}$ are transmitted through the high density fuel around the emitting hot-spot. At energies high enough to be transmitted with absorption, for example $20 \mathrm{keV}$, the image is virtually indistinguishable from the neutron image. At $8 \mathrm{keV}$, significant absorption features begin to 
appear. Since those tend to be in spikes that are plunging down into the hot-spot, they correspond to the less-emitting areas of the image and tend to exaggerate the structure. It would be useful to have images at a variety of energies, to reconstruct both the emission and absorption.

\section{Summary}

We are using increasingly detailed modeling, on a variety of NIF ignition targets, to understand the available parameter space and to set specifications. HYDRA 3D simulations have been done with more than adequate solid angle and resolution to ensure accurate modeling of the Rayleigh-Taylor instability growth. We have a suite of designs spanning $250 \mathrm{eV}$ to $350 \mathrm{eV}$, with the optimum still looking like it is close to $300 \mathrm{eV}$. Finally, specifications for target fabrication and diagnostic instrumentation are challenging but appear viable.

[1] S.W. Haan, S.M. Pollaine, J.D. Lindl, L.J. Suter, R.L. Berger, L.V. Powers, W.E. Alley, P.A. Amendt, J.A. Futterman, W.K. Levedahl, M.D. Rosen, D.P. Rowley, R.A. Sacks, A.I. Shestakov, G.L. Strobel, M.Tabak, S.V. Weber, G.B. Zimmerman, W.J. Krauser, D.C. Wilson, S.V. Coggeshall, D.B. Harris, N.M. Hoffman, and B.H. Wilde., Phys. Plasmas 2, 2480 (1995)

[2] W.J. Krauser, N.M. Hoffman, D.C. Wilson, B.H. Wilde, W.S. Varnum, D.B. Harris, F.J. Swenson, P.A. Bradley, S.W. Haan, S.M. Pollaine, A.S. Wan, J.C. Moreno, and P.A. Amendt, Phys. Plasmas 3, 2084 (1996).

[3] D. C. Wilson, P.A. Bradley, N.M. Hoffman, F.J. Swenson, D.P. Smitherman, R.E. Chrien, R.W. Margevicius, D.J. Thoma, L.R. Foreman, J.K. Hoffer, S.R. Goldman, S.E. Caldwell, T.R. Dittrich, S.W. Haan, M.M. Marinak, S.M. Pollaine, and J.J. Sanchez., Phys. Plasmas 5, 1953 (1998).

[4] J. D. Lindl, Inertial Confinement Fusion : The Quest for Ignition and Energy Gain Using Indirect Drive, Springer Verlag, New York (1998).

[5] M. M. Marinak, R. E. Tipton, O. L. Landen, T. J. Murphy, P. Amendt, S. W. Haan, S. P. Hatchett, C. J. Keane, R. McEachern, and R. Wallace, Phys. Plasmas 3, 2070 (1996).

[6] G. B. Zimmerman and W. L. Kruer, Comments Plas. Phys. 2, 51 (1975).

[7] M.M. Marinak, S.G. Glendinning, R.J. Wallace, B.A. Remington, K.S. Budil, S.W. Haan, R.E. Tipton, and J.D. Kilkenny, Phys. Rev. Lett 80., 4426 (1998).

[8] M.M. Marinak, S.W. Haan, T.R. Dittrich, R.E. Tipton, and G.B. Zimmerman, Phys. Plasmas 5, 1125 (1998).

[9] T. R. Dittrich, S. W. Haan, M. M. Marinak, S. M. Pollaine, and R. McEachern, Phys. Plasmas 5, 3708 (1998).

[10] R. D. Petrasso, C. K. Li, M. D. Cable, S. M. Pollaine, S. W. Haan, T. P. Bernat, J. D. Kilkenny, S. Cremer, J. P. Knauer, C. P. Verdon, R. L. Kremens, Phys. Rev. Lett. 77, 2718 (1996). 